\section{AATS Week 2018 Call for Abstracts and Videos}

The AATS welcomes you to submit your abstracts and videos to AATS Week 2018 for consideration at the:

AATS Aortic Symposium, April 26-27, 2018, in New York, NY

Submission Deadline: Monday, December 18, 2017 at 11:59 pM Eastern Time
AATS Annual Meeting, April 28-May 1, 2018, in San Diego, CA

Submission Deadline: Sunday, October 15, 2017, at 11:59 PM Eastern Time

For additional information regarding submission categories and deadlines, please visit www.aats.org.

\section{The AATS Graham Foundation}

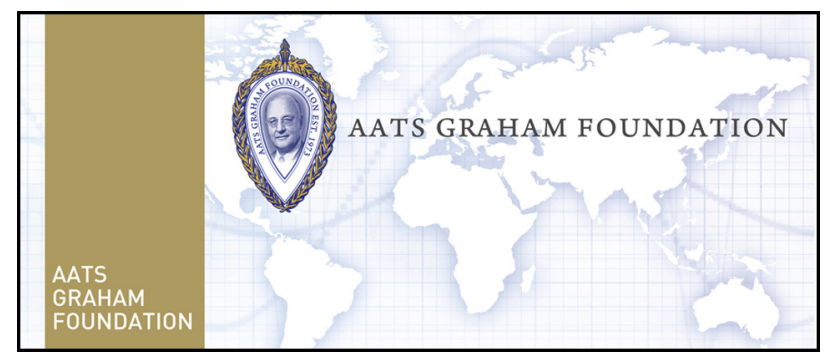

\section{Invest in the Future}

Every day, CT surgeons transform the lives of their patients around the world. Your support is essential to ensure the future of our specialty and continue advancing global innovation in CT surgery. Please make a gift to the Graham Foundation or renew your commitment. Together, we can promote our specialty not only for the next generation of surgeons, but also the patients they serve.

Learn more about individual and corporate/organizational giving opportunities.

Visit the Graham Foundation Web site: www.aatsgra hamfoundation.org

Contact the AATS Development Office: 978-252-2200, Ext. 544

\section{The Western Thoracic Surgical Association}

\section{Applications for Membership}

The WTSA is now accepting Applications for Membership online for Active as well as Candidate membership status for the 2018 membership cycle. Visit the WTSA Web site at www.westernthoracic.org to read the complete membership eligibility requirements and to initiate an online application.

\section{Active Member}

$\$ 375.00$ annually, plus $\$ 50.00$ initiation fee

Applicant must meet all membership criteria, including but not limited to:

- Reside within or have completed a cardiothoracic residency training program within the geographic limits of the Association.

- Have been engaged in the practice of thoracic and cardiovascular surgery for at least three years following completion of postgraduate training. If a candidate completed his/her thoracic surgical residency or a one-year clinical fellowship in an institution within the geographic limits of the Association, such completion may count toward one of the three years of practice.
- Have a full and unrestricted license to practice medicine in his or her respective state or province, and have a current appointment on the surgical staff of a hospital with no reportable action pending which could adversely affect such applicant's staff privileges at any hospital.

\section{Candidate Member}

$\$ 100.00$ annually

Applicant must meet all membership criteria, including but not limited to:

- Be matched or enrolled in either a cardiothoracic surgery education program accredited by the Residency Review Committee for Thoracic Surgery under the authority of the ACGME or a program approved for cardiothoracic surgery education by the Royal College of Surgeons of Canada-or their equivalency-from within the Association's geographic limits. Individuals who have completed their education in one of the above programs but do not yet meet all of the criteria for Active membership also are eligible to apply for Candidate membership. Individuals who trained outside the Association's geographic limits who are now residing within the Association's boundaries but do not yet have three years in practice may also apply for Candidate membership. 
An application must include the following uploads: a photo, a complete curriculum vitae with bibliography, and, for Active applicants, the 3 most significant articles that s/he personally wrote. The application must be completed and submitted online by March 1, 2018, and all support letter(s) (three for Active applicants, one for Candidates) uploaded by that applicant's sponsor(s) by March 31, 2018, in order for the applicant to be considered for election to membership at the 2018 Annual Meeting.
WTSA 44th Annual Meeting

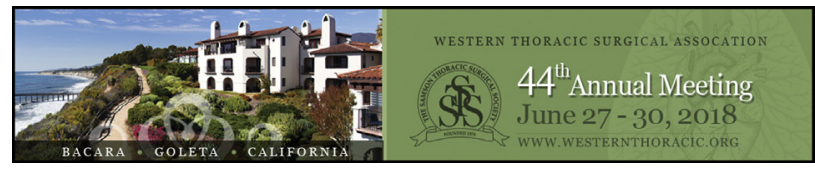

Save the Date!

June 27-30, 2018

The Bacara

Goleta, California

\section{The American Board of Thoracic Surgery}

\section{ABTS Announcement}

The American Board of Thoracic Surgery's Maintenance of Certification program was adopted 7 years ago. Since that time, there has been a continuous evaluation in the Board's thinking about the overall process, based upon internal discussions and input from our diplomates.

These inputs resulted in our decision to migrate from a purely knowledge-based multiple-choice exam, using a Pearson Testing Center, to a Mastery Learning Process, using a SESATS format. Diplomates, enrolled in this year's (2015) 10-year MOC process, will fulfill their Part III requirement by completion of a home or office-based secure learning exam, following the instructions on the ABTS Web site.

In brief, you will be directed to a secure Web site, administered by Software Secure. The only special computer hardware needed will be a camera for your home or office computer (most laptops now come with a built-in camera). Once logged in, you will be asked to verify your identity by holding up your driver's license with your picture next to your face. You will be visually monitored for the time you are logged onto the Web site.

There are 100 SESATS questions (primarily taken from SESATS X), based on your specialty designation (Adult Cardiac, General Thoracic, Cardiothoracic, and Congenital), that you will need to work through as instructed. The exam will now be modular and tailored to your practice-for example, if your practice is $100 \%$ adult cardiac, you will only have adult cardiac and critical care questions. You will have 15 hours with as many as 10 logins to complete the 100 questions during the months of September and October 2015. For those diplomates who have used SESATS in the past, the process of working through the questions is the same. For those who aren't familiar with SESATS, it might be beneficial to purchase and download SESATS X and work through the specialty-specific module. This preparation will give you familiarity with the process. While SESATS X may be helpful preparation, it is not required.

The goal of this exam is to provide a learning opportunity using judgement and decision making as well as knowledge. There is no grade involved, but you will be given the percentage of questions you answered correctly on the first try.

Not passing this exam would result from either not completing the 100 questions in the 15-hour and 10-login limit or by rushing through the questions without reading the critique. The Board and MOC Committee believe that reading the critique is key to the learning process using SESATS. The Software Secure reporting system will allow us to verify the pace of completion and thus limit the passing grades to those who earnestly participate in the process.

The Board sincerely hopes that this pilot of life-long learning is viewed favorably by our diplomates. If the diplomates find this form of learning better than the previous approach that used a secured multiple-choice test administered in a remote testing center, the Board will continue with this new strategy and refine SESATS as we go forward to assure that new standards of care are communicated to members of the ABTS community as part of the MOC process. There will be a brief survey following the last SESATS question, which needs to be completed to officially finish the process.

Everyone at the ABTS thanks you for embracing the primary principle of MOC-life-long learning, which is consistent with our obligation to the public trust.

\section{ABTS Requirements for the 10-Year Milestone for Maintenance of Certification}

Diplomates of the American Board of Thoracic Surgery (ABTS) who plan to participate in the 10-Year Milestone 